
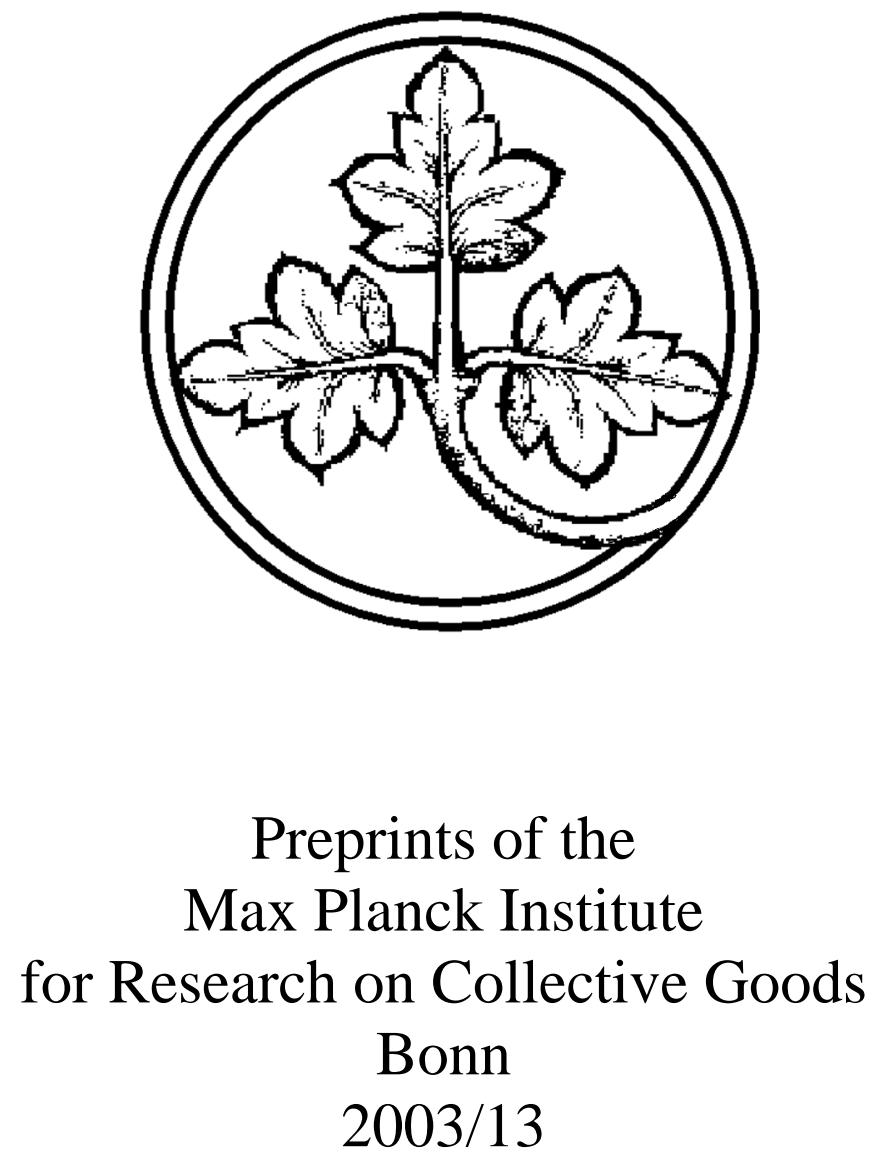

Learning, Institutions and Economic Performance

C. Mantzavinos, Douglass C. North, Syed Shariq 


\title{
Learning, Institutions, and Economic Performance
}

\author{
C. Mantzavinos, Douglass C. North, Syed Shariq
}

December 2003 


\title{
Learning, Institutions, and Economic Performance
}

\author{
By C. Mantzavinos, Douglass C. North, and Syed Shariq
}

\begin{abstract}
In this article, we provide a broad overview of the interplay among cognition, belief systems, and institutions, and how they affect economic performance. We argue that a deeper understanding of institutions' emergence, their working properties, and their effect on economic and political outcomes should begin from an analysis of cognitive processes. We explore the nature of individual and collective learning, stressing that the issue is not whether agents are perfectly or boundedly rational, but rather how human beings actually reason and choose, individually and in collective settings. We then tie the processes of learning to institutional analysis, providing arguments in favor of what can be characterized as "cognitive institutionalism." Besides, we show that a full treatment of the phenomenon of path dependence should start at the cognitive level, proceed at the institutional level, and culminate at the economic level.
\end{abstract}

Forthcoming in: Perspectives on Politics, vol. 2, Nr. 1, 2004

C. Mantzavinos is a senior fellow at the Max Planck Institute for Research on Collective Goods, Bonn, Germany (mantzavinos@mpp-rdg.mpg.de).

Douglass C. North is the Spencer T. Olin Professor in Arts and Sciences at Washington University in St. Louis (batt@wueconc.wustl.edu).

Syed Shariq is a senior fellow at the Institute for International Studies, Stanford University (sshariq@stanford.edu). For acknowledgements, please see footnote 1. 
The greatest challenge for the social sciences is to explain change-or more specifically, social, political, economic, and organizational change. ${ }^{1}$ The starting point must be an account of human learning, which is the fundamental prerequisite for explaining such change. The ability to learn is the main reason for the observed plasticity of human behavior, and the interaction of learning individuals gives rise to change in society, polity, economy, and organizations. Because learning is the main object of inquiry in cognitive science, only a dogmatic attitude would prevent social scientists interested in phenomena related to change from paying appropriate attention to its findings. The revolution over the past decades in cognitive science has produced valuable insights regarding the processes of individual learning across different types of environments. This is the main reason why cognitive science is not merely of peripheral importance for social scientists, but should be the starting point for any serious discussion of societal change.

In this article, we explore the nature of individual learning and then proceed with an examination of collective learning and with a discussion of the emergence of institutions. We then provide a link between learning and overall economic performance and, in the end, examine the issue of path dependence.

\section{Individual Learning}

Research in cognitive science during the past decades has deepened our knowledge of the relationships among brain, mind, and behavior. In particular, work in the approaches known as "cognitive neuroscience" has advanced our understanding of how brain structures are linked to mental phenomena and observable behavior. ${ }^{2}$ The cognitive architecture of Homo sapiens being the product of a long evolutionary process, a major issue that confronts us is the interplay between the genetic structure that has evolved in response to the evolving human environment and the cultural conditions that are a consequence of the institutional framework deliberately created by humans to order their environment.

1 Versions of this article have been presented at the Second Knexus Research Symposium on Institutionalization of Knowledge at the Institute for International Studies, Stanford University, in August 2000; at the Cognition, Learning, and Social Change workshop in Arlington, Virginia, in October 2000; at the Beliefs, Institutions, and Social Change workshop at Washington University, St. Louis, in December 2000; at the Politics, Markets, and Social Change workshop at Stanford University, in February 2001; at the fifth annual conference of the International Society for New Institutional Economics at the University of California, Berkeley, in September 2001; at the Institutions and Institutional Change workshop at the Max Planck Institute for Research on Collective Goods, in October 2001; and at the annual meeting of the American Political Science Association in Boston, in September 2002. We thank all participants of the above workshops and sessions for their helpful comments and suggestions. We are particularly grateful for valuable comments by Jim Alt, Martin Beckenkamp, Jeannette Colyvas, Bob Cooter, Leda Cosmides, Tyler Cowen, Frank Dobbin, Merlin Donald, Paul Edwards, Christoph Engel, Jean Ensminger, Henry Farrell, Alexander Field, Neil Fligstein, Mark Granovetter, Avner Greif, Peter Hall, Adrienne Heritier, David Holloway, Katharina Holzinger, Ron Jepperson, Jim Johnson, Phil Keefer, Sukkoo Kim, Jack Knight, Anjini Kochar, Timur Kuran, Dick Langlois, David Laitin, Margaret Levi, Stefan Magen, Kevin McCabe, Dan McFarland, Jim March, Bertin Martens, Terry Moe, Joel Mokyr, Wolfgang C. Müller, John Nye, John Padgett, Perri 6, Paul Pierson, Woody Powell, Birger Priddat, Nathan Rosenberg, Norman Schofield, Richard Scott, Christian Schubert, Itai Sened, Paul Sniderman, Alec Stone Sweet, John Tooby, Mark Turner, Morten Vendelo, Karen Vaughn, Barry Weingast, Gavin Wright, Jennifer Hochschild, and three anonymous reviewers.

Damasio 1999. 
Because cognitive science is a very young discipline, there are, not surprisingly, a number of competing explanations for perception, learning, memory, and attention; even more controversy surrounds overall explanations of the nature of the cognitive processes and the interplay between mind and brain. In order to usefully apply cognitive science to political science, economics, and other social sciences, it is important to remember the analytical focus of the explanatory enterprise. For our purpose - coming to grips with the issue of societal change- - we want to use theory that is sufficiently analytic to provide the following:

_ $\quad$ an empirically testable account of individual learning.

- $\quad$ a satisfactory account of choice processes.

- a foundation for explaining the processes of social learning, since the ultimate phenomena of interest are political change and economic outcomes.

In light of these criteria, we need not engage certain questions debated in cognitive science-for example, concept formation, which involves complicated interaction among genetics, neuroembryology, cellular mechanisms, maturation processes, neuronal group formation, and ontogenetic experience. ${ }^{3}$ For the most part, we do not need to take a stand on the details of these processes, since we are concerned only with conceptualizations that show great variety across social groups and that can undergo substantial change even within one generation. The mental operations that underlie this kind of variety are creative and flexible, so we are restricting our claims to them and the malleable mental representations they produce. We do not dive into the contentious debate over concepts that are much more basic and, in many cases, evidently universal across the species (such as basic force dynamics, certain aspects of the structure of color, chase play, et cetera).

The approach that we suggest views the mind as a complex structure that actively interprets and at the same time classifies the varied signals received by the senses. The mind classifies the experiences from the physical environment as well as those from the sociocultural-linguistic environment. ${ }^{4} \mathrm{~A}$ wide variety of mental representations have been offered as cognitive models to describe the mental operations that are of interest here. ${ }^{5}$ In spite of the ongoing and as yet inconclusive debate among the proponents of the different conceptualizations of mental models, ${ }^{6}$ we find that the pragmatic notion of mental models is the most appropriate for the explanatory purposes here. Mental models gradually evolve during our cognitive development to organize our perceptions and keep track of our memories. As flexible knowledge structures, they are

3 We are grateful to an anonymous reviewer for suggesting the argument around which this paragraph has been developed.

Gigerenzer 2000.

Pitt 2002.

See, e.g., Fetzer 1999a; Fetzer 1999b; Johnson-Laird 1997a; Johnson-Laird 1997b; Johnson-Laird and Byrne 1999; Rips 1994; Rips 1997. 
typically formed by an organism in pragmatic response to a problem situation, in order to explain and interpret its environment. ${ }^{7}$

A mental model can best be understood as the final prediction that the mind makes or expectation that it has regarding the environment before getting feedback from it. Depending on whether the expectation formed is validated by the environmental feedback, the mental model can be revised, refined, or rejected altogether. Learning is the complex modification of the mental models according to the feedback received from the environment. The unique feature of human learning is that the modification of mental models goes hand in hand with "representational redescription," environment is subsequently reordered to serve as the solution to a wide variety of problems.

The formation of mental models and the testing of solutions to problems in the environment do not necessarily lead to success, however. Learning is an evolutionary process of trial and error, ${ }^{9}$ and failure to solve a problem leads to the trial of a new solution. Because mental models are generally flexible cognitive structures that help humans solve their problems, it is interesting to consider further the relationship between environmental feedback and the stabilization or modification of mental models.

When environmental feedback confirms the same mental model many times, it becomes stabilized, in a way. We call this relatively crystallized mental model a "belief"; and we call the interconnection of beliefs (which can be either consistent or inconsistent) a "belief system." Having enabled an individual to survive in his or her environment in the past, the belief system becomes connected with the motivational system. To put it another way: the belief system is progressively shaped by the involvement of a parallel emotional adaptation, and it therefore takes on the character of a general filter for all new stimulus processing, so one may safely hypothesize that it is relatively resistant to abrupt changes.

When a solution produced on the basis of a certain mental model has not succeeded, an individual employs inferential strategies_especially analogies_in a quasi-automatic way. ${ }^{10}$ If these strategies do not solve the problem either, then the individual is forced to become creative-that is, to form new mental models and try new solutions. This is the case of choice, best conceptualized as the mental probing of alternatives in order to solve a new problem. ${ }^{11}$

Holland et al. 1986.

Clark and Karmiloff-Smith 1993.

Popper 1992 [1972].

$10 \quad$ Nisbett and Ross 1980; Holyoak and Thagard 1995; Gentner et al. 2001.

11 See Mantzavinos 2001. As the cognitive neuroscientist Elkhonon Goldberg puts it (in Goldberg 2001, 44):

The brains of higher animals, including humans, are endowed with a powerful capacity of learning. Unlike instinctive behavior, learning, by definition, is change. The organism encounters a situation for which it has no ready-made effective response. With repeated exposures to similar situations over time, appropriate response strategies emerge. The length of time, or the number of exposures required for the emergence of effective solutions, is vastly variable. The process is sometimes condensed in a single exposure (the so-called Aha! Reaction). But invariably, the transition is from an absence of effective behavior to the emergence of effective behavior. This process is called "learning" and the emergent (or taught) behavior is called "learned behavior." At an early stage of every learning process the organism is faced with "novelty," and the end stage 
Environmental feedback plays a primary role in determining the success or failure - and the subsequent incremental stabilization or modification —of the underlying mental models. In sum, whether creative choice or learning will take place depends crucially on the environmental feedback that the individual mind receives while trying to solve its problems. Obviously, nothing guarantees that the reception of environmental feedback will occur accurately. Because the mind actively interprets all sensory input, the message regarding the success or failure of the solution attempted will often be misinterpreted. Indeed, the persistence throughout history of dogmas, myths, superstitions, and ideologies based on such flawed belief systems calls us to pay as much attention to learning that produces such beliefs as we do to learning that appears to interpret correctly the problems confronting humans.

The theory that we suggest here needs further elaboration, of course. But it provides, we think, a useful starting point for building our analytical framework because it meets all three criteria previously proposed. It gives a more or less satisfactory account of both individual learning and choice processes, while providing a sufficient basis in order to explain the processes of social learning, to which we turn now.

\section{Collective Learning and Change}

Learning at the societal level can be best conceptualized as a process of shared or collective learning. When we attempt to explain the emergence of social or cultural knowledge, we must distinguish two aspects of shared learning: the static and the evolutionary.

In the static dimension, individuals in a given sociocultural environment continually communicate with other individuals while trying to solve their problems. The direct result of this communication is the formation of shared mental models, ${ }^{12}$ which provide the framework for a common interpretation of reality and give rise to collective solutions to the problems arising in the environment. The importance of this process is obvious: a common interpretation of reality is the foundation of any further social interaction.

What about the evolution of the shared mental models in a social group over time? The evolution of shared mental models - that is, shared or collective learning-depends on the group size and is therefore different within organizations and in the society overall. Shared learning first takes place within families, neighborhoods, and schools (that is, within organizations). The modern theory of organizational learning views organizations as systems of distributed knowledge in which capabilities are shared through knowledge exchange. ${ }^{13}$ At the level of society, the process of cultural evolution concerns the growth and transmission of knowledge in time. Merlin Donald stresses the importance of "External Symbolic Storage" for the transmission and accumulation of

of the learning process can be thought of as "routinization” or "familiarity.” The transition from novelty to routinization is the universal cycle of our inner world. It is the rhythm of our mental processes unfolding on various time scales [our italics].

12 Denzau and North 1994.

13 March 1999. 
knowledge across generations. The critical innovation that has massively supported the evolution of "theoretic" culture is the simple habit of recording ideas-i.e., of "externalizing the process of oral commentary and events.” This phenomenon occurred in China, India, Egypt, and Mesopotamia for at least a thousand years before it took hold in ancient Greece, at around 700 B.C. The new element then was that "for the first time in history complex ideas were placed in the public arena, in an external medium, where they could undergo refinement over the longer term, that is, well beyond the life-span of single individuals." 14 These External Symbolic Storage networks have decisively driven forward theoretical knowledge-knowledge communicable by means of symbols (natural and artificial) — because they provide the possibility of a constant interaction between the corpus of theoretical-scientific knowledge and the theoretical problems of the individuals in a society.

The stock of knowledge transmitted from generation to generation is not limited to theoretical knowledge, however. The other category of knowledge-practical knowledge, or "knowing how" ${ }^{\prime 15}$ - is not expressible in linguistic terms; the mechanism of its transmission is the direct imitation of the performance of others. Practical knowledge refers to all skills acquired by solving practical problems — swimming, cooking, riding a bicycle, driving a car, typing a paperand is equally important for the everyday life of all individuals in a society. ${ }^{16}$

As collective learning takes place at the societal level, the problem-solving capacity of the society, encompassing both theoretical-scientific and practical knowledge, grows and is transmitted over time. There is, however, a subcategory of practical knowledge-the knowledge concerning the solution of social problems of human interaction-that in many cases cannot be understood as having grown through time. At this point, we must go beyond Friedrich A. von Hayek, who equated the growth of civilization with the growth of knowledge, including "our habits and skills, our emotional attitudes, our tools and our institutions-all adaptations to past experience which have grown up by selective elimination of less suitable contact." ${ }^{17}$ We must develop a more analytic understanding of societal institutions and examine in some depth how they evolve.

$14 \quad$ Donald 1991, 342, 344.

15 Ryle 1949.

16 This distinction between theoretical and practical knowledge parallels the one between declarative and procedural knowledge drawn in cognitive psychology. See, e.g., Anderson 1993, chapters 2-4. For evidence that the difference between "knowing that" and "knowing how" is honored by our nervous system, see Cohen and Squire 1980. 


\section{Collective Learning and the Emergence of Institutions}

Institutions are the rules of the game in a society or, more formally, the humanly devised constraints that structure human interaction. They consist of formal rules (constitutions, statute and common law, and regulations), informal rules (conventions, moral rules, and social norms), and the enforcement characteristics of each. Because they make up the incentive structure of a society, they define the way the game is played through time. When theorizing about institutions, it is useful to distinguish between two aspects: external and internal.

From an external point of view, institutions are shared behavioral regularities or shared routines within a population. From an internal point of view, they are nothing more than shared mental models or shared solutions to recurrent problems of social interaction. Only because institutions are anchored in people's minds do they ever become behaviorally relevant. The elucidation of the internal aspect is the crucial step in adequately explaining the emergence, evolution, and effects of institutions; it is this that makes for the qualitative difference between a cognitive approach to institutions and other approaches. Although, for example, the rational choice approach sheds some light on cognitive processes, it does so in a standardized way, viewing all mental events as choices that lead to actions. While paying due attention to choice phenomena, the cognitive approach to institutions does not insist on their rationality as judged by some external standard, nor does it neglect the wider range of mental processes-analogical reasoning, skill formation, et cetera-that play a crucial role in the emergence of shared solutions to recurrent problems of social interaction (i.e., institutions).

Institutions have diverse effects. One is the provision of incentives to create organizations. Here, it is useful to distinguish institutions from organizations. Institutions are the rules of the game; organizations are the players. The latter consist of groups of individuals bound together by some common objective. For example, firms are economic organizations, political parties are political organizations, and universities are educational organizations. As shared mental models evolve within organizations, collective learning takes place with respect to their goals. ${ }^{18}$

The emergence of informal and formal institutions is driven by distinct mechanisms. A society's informal institutions emerge and change in a process of spontaneous interaction and are "indeed the result of human action, but not the execution of any human design."19 The spontaneous emergence of informal institutions is a process of innovation and imitation that takes place in a social group that is learning collectively. Individuals respecting conventions, following moral rules, and adopting social norms cause (as an unintended outcome of their action) the emergence of social order. In close-knit groups, informal institutions largely suffice to stabilize expectations and provide discipline, because the members of the group engage in personal relationships. ${ }^{20}$ In primitive societies, informal institutions alone can establish social order; and often there is no need for additional institutions with an explicit third-party enforcement mechanism.

$18 \quad$ Powell and DiMaggio 1991.

19 Ferguson 1966 [1767], 188.

20 For substantial empirical work on this issue, see Ostrom 1990 and Ostrom et al. 1994. 
This brings us to one of the core issues in political science: the reasons for state existence. States exist because they provide individuals with solutions to the twin problems of trust and protection from aggression (by individuals of the same society and ones of different societies). A state emerges once a society grows bigger and relationships among the members become increasingly impersonal. In cases of larger groups or societies, trust becomes scarce since the discipline of reciprocity and the "shadow of the future" are relatively low. Individuals capable of learning are bound to realize that when they act within a large group, the probability of dealing with a defector increases. Because - as we have explained above - the content of an individual's learning depends decisively on environmental feedback, individuals acting in a large group (e.g., a modern, complex society) will acquire different lessons than will those in a small group (e.g., a primitive tribe). This differentiated learning process is central to whether the state emerges as an agency of enforcement.

In a large society, for instance, with its advancing impersonalization, it is sufficient for the process of state emergence to begin if a creative individual starts cheating on the promises given by the rest of the group members, realizing the potential benefit of defection. Others will imitate him; and after some time, an increasingly large number of free riders will come to be. As a consequence, the environmental input of the other (noncheating or moral) individuals will change. They will have collectively learned that cooperation is beneficial, but that defectors exist in increasing numbers, and that the costs of punishing the defectors have increased because there are so many.

This collective lesson has an important implication: in order to prevent free riding, a demand for protection will arise. Each individual will try to solve this practical problem by calling for violence against free riders. The satisfaction of this demand can take place in two ways: either every single individual will consume some of his productive capacity and time in order to form coalitions against free riders each time they defect, or an agency that specializes in protection against free riders will emerge. Considering the immense transaction costs in the first scenario, it is plausible to hypothesize that some creative individuals will establish and run a business providing protection.

There is no reason to assume that only one protective agency will emerge. On the contrary, many such agencies will exist within a society, trading their protection against free riders for money or other goods. The peculiarity of this good is that violence offers, in fact, the opportunity to the protective agencies to oppress the same group members that it is meant to protect. The entrepreneurs running those agencies are bound only by the informal rules of the game that are relevant for all members of the society in question-i.e., the conventions, moral rules, and social norms prevalent at the time.

Since only informal rules of the game exist, and the entrepreneurs have access to a violence mechanism, three kinds of relationships are possible among the protective agencies: they may cooperate with one another, compete, or remain indifferent. In a trial-and-error process, they will engage in all possible relationships, ranging from armed battles to complete fusion of protective 
agencies in order to obtain better control over the customers. The outcome of this evolutionary process cannot be fully determined ex ante, since it depends on the creativity of the entrepreneurs (or rulers), their estimated chances to win the battles, and the effectiveness of their control over their customers.

We must cautiously address the question of whether only one protective agency will prevail in the end, successfully claiming a monopoly through the legitimate use of force in a territory (Max Weber). ${ }^{21}$ The monopoly view of the state is only partly correct. It is surely fallacious if the alleged monopoly of force is meant to cover the whole society or cultural community - that is, all individuals with shared mental models and informal institutions. Historical counterexamples include the independent Greek city-states of antiquity and the feuds in the Middle Ages. ${ }^{22}$ In a narrower sense, however, the argument concerning the monopoly of force is correct: the protective agencies possess a monopoly over the group of individuals that they protect. ${ }^{23}$ The cooperative or competitive processes among different protective agencies, each one using a monopoly of force over its own group of clients, can—but do not necessarily-lead to a monopolistic outcome.

Thus, in an evolutionary process characterized by collective learning, division of labor, and competition or cooperation among entrepreneurs, one or more protective agencies remain in the society. Since their primary function is to offer protection in exchange for goods or money, they constitute the protective state or states taxing constituents for the supplied protection.. But isn't there any difference between protective agencies and protective states? The only analytically important one seems to be that protective agencies appear at the first stages of the evolutionary process, whereas protective states are, in a way, the outcome of that process. Greater stability is characteristic of the protective state, since both rulers and citizens have already gone through a learning process. Citizens have realized that the costs of exiting a protective state are quite high (if exit is not explicitly allowed by the rulers ${ }^{24}$ ); and rulers have learned how other rulers react

21 Weber 1972 [1922], 29.

22 In ancient Greece, for example, we have a clear case of a cultural community with similar or even identical informal institutions; it is well known that Greeks identified themselves as nonbarbarians and that a Greek was defined as anybody sharing the Greek culture. This, however, went hand in hand with a great variety of protective agencies in the form of city-states that offered protection in an autonomous way, periodically engaging in all kinds of relationships with one another. So here is a case in which a monopoly of force does not cover the whole cultural community. The feuds in the Middle Ages provide an obvious similar case.

23 It is important to note that the reason for this monopoly does not have anything to do with economic arguments concerning economies of scale and the like. There is no evidence that protection is an industry that could be considered a natural monopoly. Rather, the monopoly of force is to be explained by reference to the ability of the protective agency to oppress its_clients and compel them to accept its protection solely. See Green 1990. On the role of relative bargaining power, transaction costs, and discount rates in regulating the relationship between rulers and constituencies, see Levi 1988, especially chapter 2.

24 Throughout most of human history, rulers have not allowed their citizens to leave their jurisdictions, because they have had an interest in taxing them. The exception is when rulers feel that their authority is being doubted. The tolerance that Castro's Cuba showed to emigrants from time to time and ostracism in ancient Greek cities are examples of exit allowance. For the argument in the text, it is crucial that exit is not free, but can only be permitted (or even commanded) by the ruler. Finer 1974. 
and which technologies of oppression are most successful. The difference is therefore one of degree rather than of kind. ${ }^{25}$

This evolutionary view is compatible with human history's great diversity. In Western Europe, there was never a hegemon after the death of Charlemagne, but there was always a plurality of rulers engaged permanently in war. Regional hegemons did prevail, however, over prolonged historical periods, as in the Ming and Manchu dynasties in China, and the Roman Empire. ${ }^{26}$

To summarize and amplify: informal institutions are produced internally - that is, they are endogenous to a community. ${ }^{27}$ By comparison, formal institutions are imposed externally onto the community as the exogenous product of the evolution of relationships among rulers._We lack a general theory of how political markets work and how protective states come to assume more and more functions, offering a bundle of public goods rather than merely protection. Though recent developments in political science have produced valuable predictions of political outcomes, ${ }^{28}$ these apply mainly to the United States and other developed polities, which operate in a network of fundamental constitutional and other political rules that remain the "unstable constants" in the short run. ${ }^{29}$ A more general theory of politics would explore the transaction-cost characteristics of political markets and the role of ideology in shaping political outcomes. ${ }^{30} \mathrm{~A}$ theory of ideology with empirical content, which has yet to be developed, could have as a starting point the evolution of the shared mental models of the political actors that give rise to and legitimize new political rules, which in turn structure human interaction. ${ }^{31}$ Choice processes would obviously be a constitutive part of such a theory, but not necessarily in the form propagated by rational choice theorists within political science. The issue is not whether individual or collective choices are to be classified as "rational" by some external normative standard, but to work out how belief systems are shared and how distributed cognition solves collective problems faced by social groups.

The relationship between formal and informal institutions is very important for policy reasons. ${ }^{32}$ Since policies consist of changes in formal institutions, but outcomes are a result of changes in both formal and informal rules (as well as enforcement characteristics), learning more about the

25 The model of state emergence that we outline in the text has strong affinities to Nozick's model (1974), though he has primarily developed it in order to draw normative conclusions that are not of interest here.

26 See Jones 1981. Our model is not meant to deny that in the modern world more complex forms of governance are prevalent. In most modern national polities, many private and public entities are authorized to monitor and enforce rules. In a national park, the rules will be enforced by a federal park ranger; in a state park, by a state park ranger; in a country park, by a country sheriff; in a city park, by city police. All of these units have considerable autonomy. The evolutionary path of some political systems leads toward strong centralized national institutions that dominate in an authoritarian manner, while the evolutionary path of others leads to a wide variety of political institutions nested at multiple levels. (On the issue of polycentricity of political order, see McGinnis 1999a; McGinnis 1999b; McGinnis 2000.) However, we focus in the text primarily on the state, because it is the most important form of governance.

28 Katznelson and Milner 2002.

29 Riker 1980.

$30 \quad$ North 1990b.

31 For a first serious attempt in this direction, see Hall 1993.

32 Nee 1998 and Nee and Ingram 1998 are first attempts to tackle this issue. 
interaction between formal and informal rules is a necessary condition for improving economic performance.

\section{Economic Performance}

Once rules are established, the next analytic step is to see how economic markets evolve within the institutional framework. Depending on the kind of institutions that prevail and their enforcement characteristics, the creation, diffusion, and division of knowledge will occur with either high or low transaction costs. Appropriate institutions, through the stabilization of expectations, lead to greater security in transactions. This process goes hand in hand with low transaction costs, better captured gains of trade, and in the end, higher economic performance. ${ }^{33}$

One can best illustrate this general argument by distinguishing between exchange and competition, and examining how they are related to knowledge division, knowledge creation, and transaction costs. Neoclassical economic theory seldom addresses this issue, and economists often use the concepts of "market" and "competition" synonymously. We define markets as exchange processes and competition as the rivalry that can take place not only in markets, but also in politics and organizations-wherever two or more individuals strive to reach the same end. We will first examine how institutions, market exchange, and the dissemination of knowledge are interrelated. Then we will address how the institutional framework affects market competition and leads to the growth and the accumulation of knowledge.

The exchange processes give rise to a division of labor, which is concomitant with a division of knowledge, among market participants. ${ }^{34}$ The fact that different individuals possess different bits of knowledge because each specializes in a specific trade or employment poses two difficult theoretical problems: coordination of knowledge and its effective use. We have stressed before that institutions are anchored in the minds of people as shared solutions to social problems. The main effect of the existence of shared mental models or shared knowledge regarding the human landscape at the cognitive level is a coordination of individual activities at the behavioral level. The members of a society build the same cognitive structures and adopt respective behavioral regularities during a long evolutionary socialization process. Thus, an individual who starts exchanging in the market already shares social rules with the other market participants. He is not an ahistorical being equipped solely with preferences that maximize utility under the constraints of, for example, given prices and available income.

During the socialization process, individuals have learned the conventions, moral rules, and social norms of their society. When they start their business, entrepreneurs have learned which legal rules they have to respect and the point to which property rights are protected or violated by the state; they are already the "legal persons" of legal theory. By having the same learning his- 
tory, entrepreneurs and the other market participants share formal and informal institutions and thus the rules of the game. This makes them the specific agents of a specific economic game.

Hence, institutions are responsible for coordinating the knowledge of market participants at a first and most important level. Clearly, depending on the characteristics of the shared learning process in specific societies, this coordination of knowledge will take place at a different level of transaction costs. ${ }^{35}$ The institutional framework of a Moroccan suq, for example, coordinates the knowledge of the market participants at higher transaction costs than the elaborate institutional framework of more differentiated markets-for instance, in the developed countries of the West.

At a second level, the coordination of knowledge in markets takes place with the aid of prices. The old Hayekian argument holds true: the existence of prices in market settings greatly facilitates the further coordination of market participants' knowledge in comparison with $^{36}$ settings without market prices_as, for example, in socialistic economic systems. The coordination of knowledge in markets is, thus, due to both the institutional framework and the prices that prevail in the specific market game.

In considering the role of the market in the accumulation of knowledge, one must look at what happens during the exchange between supply and demand, provided that all market participants know the rules of the game. The exchange is a communication process, during which consumers and entrepreneurs form shared mental models. Thus, entrepreneurs and consumers do not at the outset share "common knowledge." ${ }^{37}$ Neither is there a fictitious auctioneer who cares that each side of the market becomes aware of the other. The very rise of the common structure of communication is the prerequisite of any exchange act. Since entrepreneurs will not always provide correct hypotheses concerning the consumers' problems, and consumers cannot possibly know all available alternatives in the markets, exchange acts are always "imperfect."

To prevent a possible misunderstanding here, we want to emphasize that the shared mental models in the exchange process are different from those that comprise the internal forms of social institutions, although they are of the same cognitive material. The distinguishing feature of the internalized rules of the game is that they are shared by all market participants. The mental models that become shared in the exchange process are, conversely, of a more temporary character; and more important, they are shared between only some consumers and some entrepreneurs. The existence of prices facilitates the formation of this kind of shared mental model during the exchange process.

Generally, the more shared mental models are formed in the market with low transaction costs, the more effective the use of knowledge in the economy will be. This argument needs further elaboration. Bertin Martens discusses the dilemma that specialized agents with limited cognitive capacity face in the division of knowledge-setting in the market. ${ }^{38}$ Agents can either devote more 
of that scarce capacity to acquiring common knowledge and forming shared mental models with other agents or build up their own specialization. Transaction costs affect which option agents will choose. A high frequency of exchange acts and a deepening of the division of knowledge lead to a greater realization of the gains of trade and, in the end, to higher economic performance.

Having examined how institutions, market exchange, and the dissemination of knowledge are interrelated, we will now see how the institutional framework affects market competition. What kind of competition prevails during the process of exchange depends crucially on the institutions that prevail at the time. Institutions determine not only the kind of competitive game, but also its tempo. So the players' tempo of learning depends on the intensity of the competition, which is in turn set by the institutional framework. ${ }^{39}$ Because of competition, the agents suffering from pecuniary external effects are motivated to learn more to ensure their survival in the economic struggle.

During the competitive process, technologies are generated as a spontaneous outcome. Why spontaneous? Because the organizations that participate in the economic game- that is, firmsare primarily concerned with increasing their profits. In the process of solving this primary problem, they employ a very wide range of competitive parameters. Technology is just one of them. Scientific knowledge is used, and also partly produced, by firms only to the degree that entrepreneurs expect economic profits from its use. So the generation of technologies is mediated by the market test-that is, by profitability considerations. This is why there is no simple causal link among institutions, organizational activity, and the generation of technologies. ${ }^{40}$

The economic competitive process that generates technologies and thus new knowledge is, of course, linked to market exchange. In order for the technologies to be effective, there must be an appropriate absorptive capacity on the demand side of the market. ${ }^{41}$ In other words, the results of the competitive process on the supply side in the form of new technologies can be wealth-enhancing only if the demand side can use them. This fact has profound implications for the important policy issue of the transmission of new technologies, especially in the less developed parts of the world. The transfer of technologies can be accomplished only if the appropriate learning processes have taken place on the receiving end. ${ }^{42}$ Thus, communication and the formation of respective shared mental models is a prerequisite of any effective use of technologies. ${ }^{43}$

In summary, economic performance is the outcome of a complex process of playing the economic game according to formal and informal rules that provide incentive structures and channel innovative activities in a certain direction. There is no guarantee that the processes of shared

39 Mantzavinos 1994.

40 Rosenberg 1994.

41 Cohen and Levinthal 1990.

42 Wright 1997.

43 Here lies a crucial difference between our theory and the endogenous growth theory (e.g., Romer 1986; Romer 1993; Romer 1994; Lucas 1988; Lucas 1993). 
learning and the institutions of a society that evolve over time will produce economic growth. ${ }^{44}$ In history the stories of failure are more frequent than the stories of success. And it is important to understand that even if we did have it right for one economy, it would not automatically be right for another; and even if we have it right today, it will not necessarily be right tomorrow. Only if we understand the principal factors that produce path dependence can we hope to be able to alter economic performance in a particular direction.

\section{Path Dependence: Cognitive, Institutional, and Economic}

The process of societal change that we presented in this article can be summarized as follows:

"reality" > beliefs > institutions > specific policies > outcomes (and, thus, altered "reality")

The feedback mechanism from outcomes to reality runs through the human mind; and because the mind interprets reality actively, we have a very limited knowledge of how outcomes will be perceived and interpreted by agents. This is the main reason why mechanistic, deterministic models of economic change cannot work: ideas are the autonomous factors of socioeconomic evolution, and if we want to learn more about this process, we need to know more about the way our minds construct reality.

Nevertheless, we can formulate a hypothesis about how the "scaffolding" that humans erect relates to outcomes while it continues to evolve over time. After a period $t_{1}$ (that is, after learning through institutions, markets, and outcomes has been completed), the mind interprets in the period $t_{2}$ reality (that is, the outcomes) on the basis of the mental models already existing in $t_{1}$. Obviously, this is true for each individual in the society, so the shared learning in $t_{2}$ must be based on what has already been there in $t_{1}$. In other words, the shared mental models in $t_{2}$ are formed on the basis of the shared mental models in $t_{1}$. In cases when the content of the shared learning is the same or similar over a number of periods, the mental models become relatively inflexible and shared belief systems are shaped. These are in turn the source of cognitive path dependence, since the more inflexible the mental models are, the more difficult their modification and revision become.

Because of this cognitive path dependence, the scaffolding of the human landscape (i.e., the formation of institutions) also takes place in a path-dependent way. Once all of the players have formed the same mental models, the institutional mix may start solving a variety of social problems in a particular way. One can speak of the "increasing returns of an institutional framework" in the sense that once the problem solutions are learned by agents, they are unconsciously applied each time similar problems arise. This institutional path dependence may structure the 
economic game in a standardized way through time and lead societies to play a game that results in undesirable consequences. ${ }^{45}$

As long as the institutional framework and the incentive structure remain constant, market interaction will be channeled into a certain direction and the generation of certain types of technologies will be encouraged. Thus, cognitive and institutional path dependence will ultimately lead to economic path dependence. The intuitively formulated proposition that "history matters" designates the importance of the phenomenon of path dependence, starting at the cognitive level, going through the institutional level, and culminating at the economic level. ${ }^{46}$

\section{Conclusion}

The analytical framework presented here provides a first approximation of the role that learning plays in the formation of institutions and in the economic games unfolded within them. Further research is needed in order to develop theories of how political markets function, of the emergence and effects of ideology, and of the relations between formal and informal institutions. For all of these research areas, the issue of learning is of crucial importance. This is why we will have to keep track of the developments in cognitive science and use its findings for our own explanatory purposes, as we move toward a more refined theory-one operational enough to be employed for policy issues. 


\section{References}

Anderson, John R. 1993. Rules of the Mind. Hillsdale, N.J.: Lawrence Erlbaum Associates.

Clark, Andy, and Annette Karmiloff-Smith. 1993. The cognizer’s innards: A psychological and philosophical perspective on the development of thought. Mind and Language 8:4, 487519.

Cohen, Neal J., and Larry R. Squire. 1980. Preserved learning and retention of pattern-analyzing skill in amnesia: Dissociation of knowing how and knowing that. Science 210, 207-10.

Cohen, Wesley, and Daniel Levinthal. 1990. Absorptive capacity: A new perspective on learning and innovation. Administrative Science Quarterly 35:1, 128-52.

Damasio, Antonio. 1999. The Feeling of What Happens: Body and Emotion in the Making of Consciousness. New York: Harcourt Brace.

Denzau, Arthur T., and Douglass C. North. 1994. Shared mental models: Ideologies and institutions. Kyklos 47:1, 3-31.

Donald, Merlin. 1991. Origins of the Modern Mind: Three Stages in the Evolution of Culture and Cognition. Cambridge: Harvard University Press.

Ferguson, Adam. 1966 [1767]. An Essay on the History of Civil Society. Edinburgh: Edinburgh University Press.

Fetzer, James H. 1999a. Deduction and mental models. Minds and Machines 9:1, 105-10. 1999b. Mental models reasoning without rules. Minds and Machines 9:1, 119-26.

Finer, Samuel E. 1974. State-building, state boundaries, and border control. Social Science Information 13:4/5, 79-126.

Gentner, Dedre, Keith J. Holyoak, and Boicho N. Kokinov, eds. 2001. The Analogical Mind: Perspectives from Cognitive Science. Cambridge: MIT Press.

Gigerenzer, Gerd. 2000. Adaptive Thinking: Rationality in the Real World. Oxford: Oxford University Press.

Goldberg, Elkhonon. 2001. The Executive Brain: Frontal Lobes and the Civilized Mind. Oxford: Oxford University Press.

Green, Leslie. 1990. The Authority of the State. Oxford: Clarendon Press.

Hall, Peter. 1993. Policy paradigms, social learning, and the state: The case of economic policymaking in Britain. Comparative Politics 25:3, 275-96. 
Hayek, Friedrich A. von 1960. The Constitution of Liberty. London: Routledge and Kegan Paul.

Holland, John H., Keith J. Holyoak, Richard E. Nisbett, and Paul R. Thagard. 1986. Induction: Processes of Inference, Learning, and Discovery. Cambridge: MIT Press.

Holyoak, Keith J., and Paul Thagard. 1995. Mental Leaps: Analogy in Creative Thought. Cambridge: MIT Press.

Johnson-Laird, Philip N. 1997a. Rules and illusions: A critical study of Rips’s “The Psychology of Proof.” Minds and Machines 7:3, 387-407.

- 1997b. An end to the controversy? A reply to Rips. Minds and Machines 7:3, 425-32.

Johnson-Laird, Philip N., and Ruth M. J. Byrne. 1999. Models rule, OK? A reply to Fetzer. Minds and Machines 9:1, 111-8.

Jones, Eric. 1981. The European Miracle: Environments, Economies, and Geopolitics in the History of Europe and Asia. Cambridge: Cambridge University Press.

Katznelson, Ira, and Helen Milner, eds. 2002. Political Science: The State of the Discipline. New York: W. W. Norton.

Langlois, Richard, and Metin Cosgel. 1998. The organisation of consumption. In The Active Consumer, ed. Marina Bianchi. London: Routledge, 107-21.

Levi, Margaret. 1988. Of Rule and Revenue. Berkeley: University of California Press.

Lipford, Jody, and Bruce Yandle. 1997. Exploring the production of social order. Constitutional Political Economy 8, 37-55.

Loasby, Brian J. 1999. Knowledge, Institutions, and Evolution in Economics. London: Routledge.

Lucas, Robert E., Jr. 1988. On the mechanics of economic development. Journal of Monetary Economics 22:1, 3-42.

—. 1993. Making a miracle. Econometrica 61:2, 251-72.

Mantzavinos, C. 1994. Wettbewerbstheorie (Theory of Competition). Berlin: Duncker and Humblot.

—. 2001. Individuals, Institutions, and Markets. Cambridge: Cambridge University Press.

March, James G. 1999. The Pursuit of Organizational Intelligence. Oxford: Blackwell Publishers. 
Martens, Bertin. 1999. The cognitive mechanics of economic development: Economic behavior as a response to uncertainty. Discussion Paper 08-99, Max Planck Institute for Research into Economic Systems.

McGinnis, Michael D., ed. 1999a. Polycentric Governance and Development: Readings from the Workshop in Political Theory and Policy Analysis. Ann Arbor: University of Michigan Press.

- ed. 1999b. Polycentricity and Local Public Economies: Readings from the Workshop in Political Theory and Policy Analysis. Ann Arbor: University of Michigan Press.

ed. 2000. Polycentric Games and Institutions: Readings from the Workshop in Political Theory and Policy Analysis. Ann Arbor: University of Michigan Press.

Nee, Victor. 1998. Norms and networks in economic and organizational performance. American Economic Review (Papers and Proceedings) 88:2, 85-9.

Nee, Victor, and Paul Ingram. 1998. Embeddedness and beyond: Institutions, exchange, and social structure. In The New Institutionalism in Sociology, eds. Victor Nee and Mary Brinton. New York: Russell Sage Foundation, 19-45.

Nisbett, Richard, and Lee Ross. 1980. Human Inference: Strategies and Shortcomings of Social Judgment. Englewood Cliffs, N. J.: Prentice Hall.

North, Douglass C. 1990a. Institutions, Institutional Change, and Economic Performance. Cambridge: Cambridge University Press.

- 1990b. A transaction cost theory of politics. Journal of Theoretical Politics 2:4, 355-67.

— 1994. Economic performance through time. American Economic Review 84:3, 359-68.

- 2000. Big-bang transformations of economic systems: An introductory note. Journal of Institutional and Theoretical Economics 156:1, 3-8.

Nozick, Robert. 1974. Anarchy, State and Utopia. Oxford: Blackwell Publishers.

Ostrom, Elinor. 1990. Governing the Commons: The Evolution of Institutions for Collective Action. Cambridge: Cambridge University Press.

Ostrom, Elinor, Roy Gardner, and James Walker. 1994. Rules, Games, and Common-Pool Resources. Ann Arbor: Michigan University Press.

Pierson, Paul. 2000. Increasing returns, path dependence, and the study of politics. American Political Science Review 94:2, 251-67.

Pitt, David. 2002. Mental representation. In The Stanford Encyclopedia of Philosophy, ed. Edward N. Zalta. Winter 2002 edition. Available at 
plato.stanford.edu/archives/win2002/entries/mental-representation. Accessed 3 December 2003.

Popper, Karl R. 1992 [1972]. Objective Knowledge: An Evolutionary Approach, seventh impression. Oxford: Clarendon Press.

Powell, Walter W., and Paul J. DiMaggio, eds. 1991. The New Institutionalism in Organizational Analysis. Chicago: University of Chicago Press.

Riker, William. 1980. Implications from the disequilibrium of majority rule for the study of institutions. American Political Science Review 74:2, 432-46.

Rips, Lance J. 1994. The Psychology of Proof: Deductive Reasoning in Human Thinking. Cambridge: MIT Press.

- 1997. Goals for a theory of deduction: Reply to Johnson-Laird. Minds and Machines, 7:3, 409-24.

Romer, Paul. 1986. Increasing returns and long-run growth. Journal of Political Economy 94:5, 1,002-37.

- 1993. Idea gaps and object gaps in economic development. Journal of Monetary Economics 32:3, 534-73.

- 1994. The origins of endogenous growth. Journal of Economic Perspectives 8:1, 3-22.

Rosenberg, Nathan. 1994. Exploring the Black Box: Technology, Economics, and History. New York: Cambridge University Press.

Ryle, Gilbert. 1949. The Concept of Mind. London: Penguin Books.

Weber, Max. 1972 [1922]. Wirtschaft und Gesellschaft. 5th ed. Tübingen: J. C. B. Mohr (Paul Siebeck).

Wright, Gavin. 1997. Towards a more historical approach to technological change. The Economic Journal 107:444, 1,560-6. 